\title{
Article \\ An All-in-One Vehicle Type and License Plate Recognition System Using YOLOv4
}

\author{
Se-Ho Park ${ }^{1}$, Saet-Byeol Yu ${ }^{1}$, Jeong-Ah Kim ${ }^{1}$ and Hyoseok Yoon ${ }^{2, *}$ (i) \\ 1 Contents Convergence Research Center, Korea Electronics Technology Institute, Mapo-gu, Seoul 03924, Korea; \\ sehopark@keti.re.kr (S.-H.P.); sbyu@keti.re.kr (S.-B.Y.); kpkk1518@keti.re.kr (J.-A.K.) \\ 2 Division of Computer Engineering, Hanshin University, Osan-si 18101, Korea \\ * Correspondence: hyoon@hs.ac.kr
}

Citation: Park, S.-H.; Yu, S.-B.; Kim, J.-A.; Yoon, H. An All-in-One Vehicle Type and License Plate Recognition System Using YOLOv4. Sensors 2022, 22, 921. https://doi.org/10.3390/ s22030921

Academic Editors: Tiago M. Fernández-Caramés and Paula Fraga-Lamas

Received: 8 December 2021 Accepted: 24 January 2022 Published: 25 January 2022

Publisher's Note: MDPI stays neutral with regard to jurisdictional claims in published maps and institutional affiliations.

Copyright: (C) 2022 by the authors. Licensee MDPI, Basel, Switzerland. This article is an open access article distributed under the terms and conditions of the Creative Commons Attribution (CC BY) license (https:// creativecommons.org/licenses/by/ $4.0 /)$.

\begin{abstract}
In smart surveillance and urban mobility applications, camera-equipped embedded platforms with deep learning technology have demonstrated applicability and effectiveness in identifying various targets. These use cases can be found in a variety of contexts and locations. It is critical to collect relevant data from the location where the application will be deployed. In this paper, we propose an integrated vehicle type and license plate recognition system using YOLOv4, which consists of vehicle type detection, license plate detection, and license plate character detection to better support the context of Korean vehicles in multilane highway and urban environments. Using our dataset of one to four multilane images, our system detected six vehicle classes and license plates with $\mathrm{mAP}$ of $98.0 \%, 94.0 \%, 97.1 \%$, and $84.6 \%$, respectively. On our dataset and a publicly available open dataset, our system demonstrated mAP of $99.3 \%$ and $99.4 \%$ for the detected license plates, respectively. From $4 \mathrm{~K}$ high-resolution images, our system was able to detect minuscule license plates as small as 100 pixels wide. We believe that our system can be used in densely populated regions to address the high demands for enhanced visual sensitivity in smart cities and Internet-of-Things.
\end{abstract}

Keywords: license plate detection; license plate recognition; make and model recognition; vehicle type detection; YOLOv4

\section{Introduction}

Computer vision applications automate repetitive tasks that require the human ability and attention to continuously monitor and make timely decisions. A profusion of such applications has been developed to detect, identify, and track various objects of interest. Recent advancements in smart city technologies [1] have enabled a plethora of visual sensors to be installed in the intelligent environment and smart infrastructure, such as closed-circuit television (CCTV), visual sensor networks [2], smart surveillance [3], intelligent traffic systems $[1,4]$, security cameras, and black boxes in vehicles. A series of state-of-the-art deep learning techniques for challenging computer vision problems [5] can detect and identify a vast number of diverse objects across categories on a grand scale. Individuals and their vehicles are significant subjects of interest in large cities and metropolitan regions, which smart cameras try to recognize. A large number of license plate recognition (LPR) [6-8] and make and model recognition (MMR) [9-11] systems have been developed to relieve human operators of the tedious task of explicitly detecting, identifying, and recognizing a wide range of cars, as illustrated in Figure 1.

In this regard, we are particularly motivated to recognize modern Korean vehicle types (VT) and Korean license plates (LP) in areas with high vehicle density in South Korea. The number of cars registered in South Korea exceeded 24 million in 2020, according to the Korean Statistical Information Service, which is roughly equivalent to one car per 2.19 people or 456.6 cars per 1000 people. Furthermore, Seoul (i.e., the capital and largest metropolis of South Korea) is one of the most surveilled cities in the world, boasting 
77,564 cameras for 234 square miles or 331.94 cameras per square mile (source: https: //www.comparitech.com/vpn-privacy/the-worlds-most-surveilled-cities/, accessed on 7 December 2021). In an ever-increasingly complex urban environment, we propose an all-in-one system named KVT-LPR which stands for Korean vehicle type and license plate recognition system, capable of identifying both VTs and LPs in the same processing pipeline.

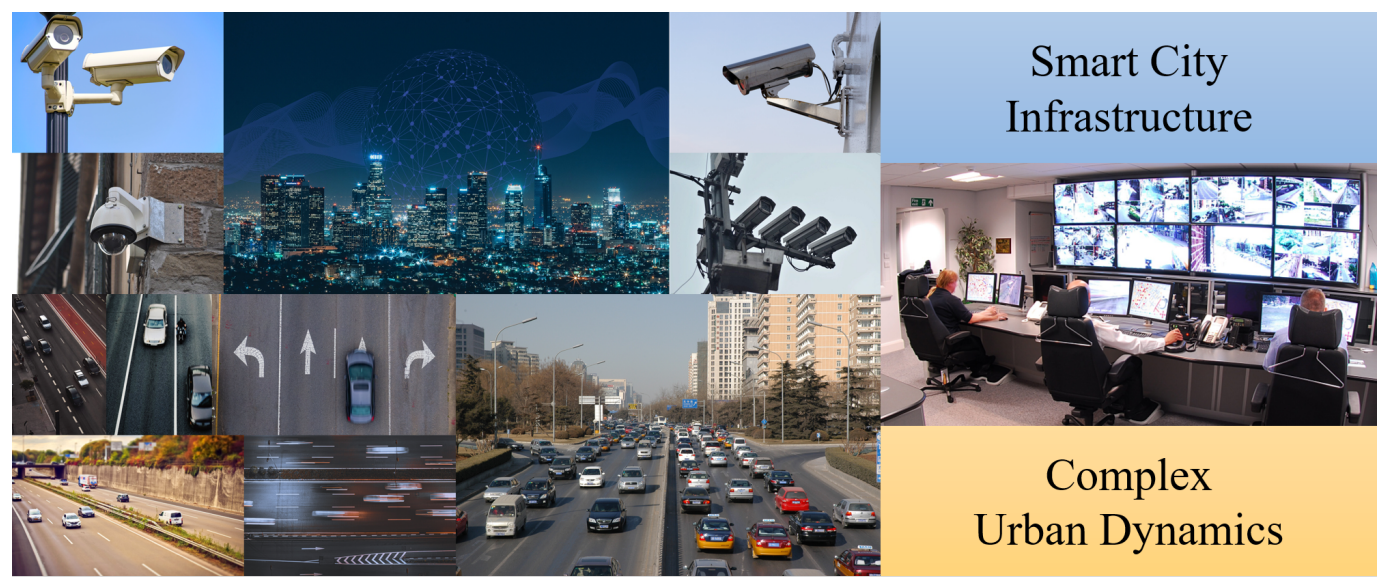

Figure 1. Pervasive visual sensors capture complex urban dynamics in smart cities.

Our contributions in this paper are as follows.

- We propose a two-phase architecture based on YOLOv4 [12] for detecting vehicle types and recognizing Korean LPs in one pipeline.

- We collect and build a custom dataset for various Korean vehicle types and LPs captured from multilanes to train and validate two custom detectors in the KVT-LPR.

- We show that the KVT-LPR effectively detects small license plates from $4 \mathrm{~K}$ highresolution input images, which is an enhancement over previous detectors.

- We demonstrate the feasibility and applicability of the KVT-LPR's practically deployed detection performance in different settings across two datasets (i.e., a custom dataset and a publicly open dataset) and two target platforms (i.e., from a high-end to an embedded solution).

\section{Related Work}

There have been a series of attempts to build faster and more accurate LPR systems. In recent years, deep learning-based approaches, such as single shot detector (SSD) [13] and You Only Look Once (YOLO)-based models [12,14-16], have been used to detect and recognize LPs. YOLO was first designed to provide fast detection speed, but it had low accuracy [14]. Despite the fact that YOLOv2 enhanced the speed and accuracy of object identification over its predecessor [15], the SSD still outperformed for smaller objects. YOLOv3's accuracy has improved since then, but its detection speed has slowed down [16]. YOLOv4 has improved performance in both speed and accuracy compared to YOLOv3 [12]. Hendry and Chen tweaked the original YOLO to create an automatic license plate recognition (ALPR) system that had a detection accuracy of $98.22 \%$ and a recognition accuracy of $78.22 \%$ [17]. Laroca et al. developed an ALPR system based on YOLO that outperformed previous systems with a recognition rate of $96.9 \%$ when tested on public datasets [18]. Castro-Zunti et al. presented an SSD-based LPR system that accurately recognized $96.23 \%$ of the Caltech Cars dataset and $99.79 \%$ of the UCSD-Stills dataset [19].

There are several related LPR systems targeting Korean LPs and sharing similar approaches. Han et al. used the cascade structure with AdaBoost learning to offer a realtime LPR identification method for high-resolution videos [20]. Park et al. developed a multinational LPR system that recognizes multiple Korean LP styles (i.e., single-line, doubleline, various layout formats) using the K-nearest neighbors method [21]. By adding spatial pyramid pooling to YOLOv3, Kim et al. developed a multiscale vehicle detection that 
outperformed other detectors [22]. For recognizing multinational LPs, including Korean LPs, Henry et al. presented an ALPR system based on YOLOv3 [23]. LP detection, unified character recognition, and multinational LP layout detection were all included in their system's architecture. Initially, they have collected and made public their own Korean automobile plate dataset, known as KarPlate. However, due to legal issues, the dataset is no longer available. Sung et al. showed Korean LP identification performance on the NVIDIA Jetson TX2 board with their custom KETI-ALPR dataset that is not open to the public using YOLOv3, YOLOv4, and SSD [24]. To recognize Korean car types, Kim et al. evaluated faster-RCNN, YOLOv4, and SSD object identification approaches [25]. Their findings revealed that YOLOv4 outperformed SSD and faster-RCNN in terms of F1 score, precision, recall, and mAP. To deal with the problem of data sparsity in the training stage, Han et al. synthesized LPs using an ensemble of generative adversarial networks (GAN) [26]. Wang et al. developed a Korean LPR approach using deep learning and KarPlate dataset (when the dataset was still available) to recognize LPs under various conditions (i.e., fog and haze) [27]. Lim and Park proposed an AI machine learning system that can use CCTV images to check illegally parked cars with the LPR function [28].

In contrast to prior research, this study investigates the application of YOLOv4 for LPR and vehicle type recognition in the Korean environment with multilanes and highresolution cameras. Table 1 compares previous studies in terms of their approaches, datasets, and system support features. Our system aims to better support the Korean context by using multilanes images collected from high-resolution cameras. The size of LPs will be small in high-resolution images. We employ YOLOv4 to recognize small LPs and vehicle types and to show that its performance is embedded-platform-ready.

Table 1. Comparison of recent Korean LPR systems.

\begin{tabular}{|c|c|c|c|c|c|c|c|}
\hline System & Approach & Dataset (Resolution) & $\begin{array}{r}\text { Korean } \\
\text { LP }\end{array}$ & Multilanes & $\begin{array}{r}\text { Small } \\
\text { LP }\end{array}$ & $\begin{array}{r}\text { Vehicle } \\
\text { Type }\end{array}$ & $\begin{array}{r}\text { Embedded } \\
\text { Platform }\end{array}$ \\
\hline Han et al. (2015) [20] & $\begin{array}{l}\text { Cascade } \\
\text { Structure }\end{array}$ & Custom $(1624 \times 1224)$ & $\mathrm{O}$ & $x$ & $X$ & $x$ & $X$ \\
\hline Park et al. (2019) [21] & KNN & Custom $(1920 \times 1080)$ & $\mathrm{O}$ & $x$ & $x$ & $x$ & $x$ \\
\hline Kim et al. (2019) [22] & YOLOv3 & UA-DETRAC $(960 \times 540)$ & $x$ & $\mathrm{O}$ & $X$ & $X$ & $X$ \\
\hline Henry et al. (2020) [23] & YOLOv3 & KarPlate $(1920 \times 1080)$ & $\mathrm{O}$ & $x$ & $X$ & $X$ & $X$ \\
\hline Sung et al. (2020) [24] & YOLOv3 & KETI-ALPR $(3840 \times 2160)$ & $\mathrm{O}$ & $x$ & $\mathrm{O}$ & $x$ & $\mathrm{O}$ \\
\hline Kim et al. (2020) [25] & $\begin{array}{l}\text { Faster-RCNN, } \\
\text { YOLOv4, SSD }\end{array}$ & Custom (N/A) & $x$ & $x$ & $X$ & $\mathrm{O}$ & $x$ \\
\hline Han et al. (2020) [26] & $\begin{array}{l}\text { LP-GAN, } \\
\text { YOLOv2 }\end{array}$ & Real + Synthetic (N/A) & $x$ & $x$ & $x$ & $x$ & $X$ \\
\hline Wang et al. (2021) [27] & $\begin{array}{r}\text { YOLOv5, } \\
\text { WPOD-NET }\end{array}$ & KarPlate $(1920 \times 1080)$ & $\mathrm{O}$ & $x$ & $\mathrm{O}$ & $x$ & $x$ \\
\hline Lim and Park (2021) [28] & DNN & CCTV images (N/A) & $\mathrm{O}$ & $x$ & $x$ & $x$ & $x$ \\
\hline Proposed (2021) & $\begin{array}{l}\text { Two phase } \\
\text { YOLOv4 }\end{array}$ & Custom $(3840 \times 2160)$ & $\mathrm{O}$ & $\mathrm{O}$ & $\mathrm{O}$ & $\mathrm{O}$ & $\mathrm{O}$ \\
\hline
\end{tabular}

\section{Proposed Methodology}

The goal of a typical LPR system is to output numbers and characters on LPs as text. Similarly, a typical MMR system identifies the vehicle's make and model from several candidates. Our goal was to create an LPR system that could identify Korean LPs and recognize a variety of Korean vehicle types as defined by the Korean vehicle classification criteria. We present an all-in-one Korean vehicle type and LP recognition system, named KVT-LPR, that employs YOLOv4 as the underlying object detector model.

Figure 2 shows the overview of our KVT-LPR using YOLOv4. The KVT-LPR aims to identify vehicle types and recognize license plates from high-resolution (i.e., $4 \mathrm{~K}$ resolution) and multilane images (i.e., one to four lanes). The details of the KVT-LPR system, including YOLOv4-based object detector and data collection processes, are elaborated in the following 
subsections. Moreover, detailed procedures of the two custom detectors (VT_LP detector and LPC detector) are visually illustrated in Section 4.

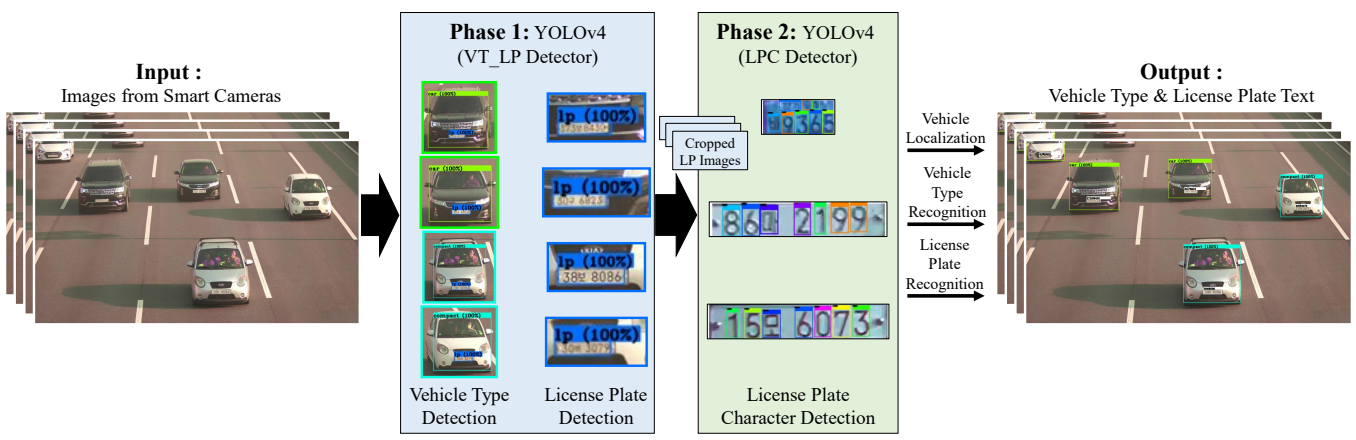

Figure 2. The overview of the KVT-LPR system.

\subsection{YOLOv4-Based Vehicle Type and License Plate Recognition}

The KVT-LPR system processes a high-resolution input image (i.e., $3840 \times 2160$ ) decoded from a high-resolution video. We collected real Korean vehicle types and LPs to build our custom dataset. Then, we used the custom dataset to train using YOLOv4 to build two custom detectors. The first detector is a VT_LP detector, which detects seven classes (i.e., six different Korean vehicle types and LPs) in the input image. The second detector is an LPC detector, which detects 68 different numbers and characters on Korean LPs. The character size of LPs is small in relation to the entire image on a high-resolution image, making character identification more challenging. To overcome this problem, we included an LP cropping procedure to the KVT-LPR, which gives the LPC detector segmented LP regions. In phase 1, vehicle types and occurrences of LPs are detected by the VT_LP detector. If LPs are found, the cropped LP image for each LP is passed into the LPC detector for phase 2. To summarize, the VT_LP detector is called first to detect vehicle types and LPs, followed by the LPC detector for each LP found. If the input image contains a large number of LPs, the KVT-LPR's overall turnaround time multiplies.

\subsection{Dataset Collection and Preprocessing}

3.2.1. Vehicle Types and LPs

We installed a camera on a highway overpass to manually record real traffic videos in order to collect various vehicle types and LP images that represent the context and environment of South Korea, as shown in Figure 3.

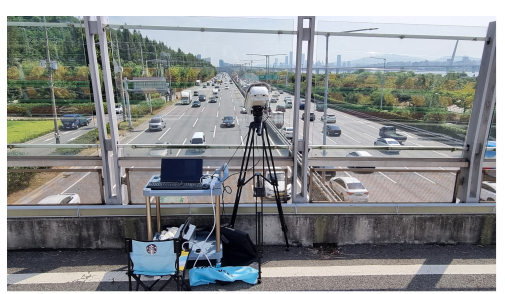

Data Collection Station

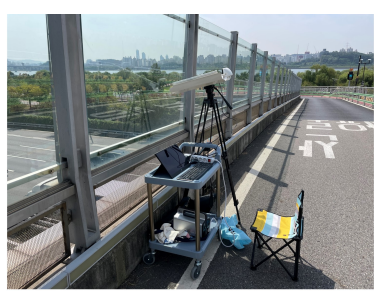

Installed Camera

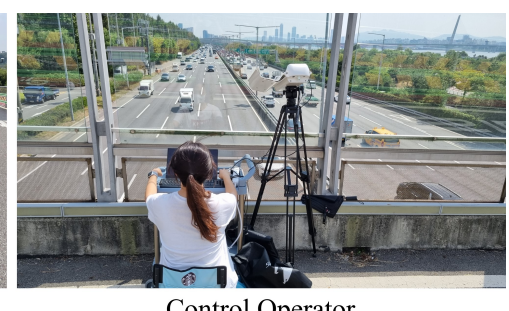

Control Operator

Figure 3. Data collection settings. Vehicles and LPs are captured using a camera fixed on a highway overpass with a residing operator controlling the data collection station.

The camera overlooking the highway (i.e., two-lane, three-lane, and four-lane) captured traffic videos at $3840 \times 2160$. We also recorded videos with a smartphone camera at $3840 \times 2160$. Images including one or more vehicles were extracted from the recorded video and used as training data for the custom detectors. Figure 4 shows examples of captured raw images that qualify for training uses. 

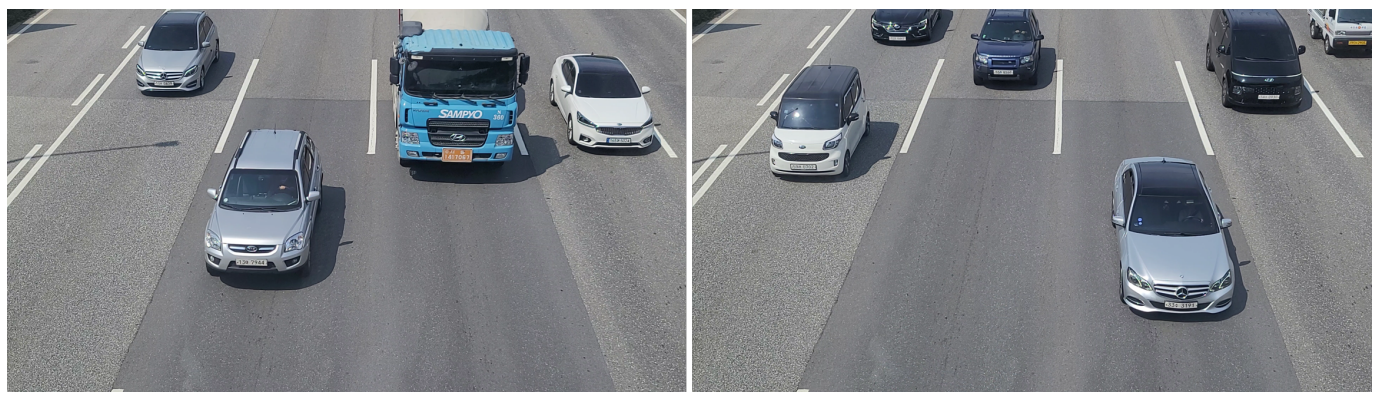

Figure 4. Examples of captured raw images from the installed camera.

The collected dataset is manually labeled by using an open-source tool LabelImg (Tzutalin (TzuTa, Canada), LabelImg, Git code (2015). https: / / github.com/tzutalin/labelImg, accessed on 7 December 2021) to annotate bounding boxes on the target objects. For example, we annotated a bounding box on LPs and the front of a vehicle covering the front window and the bumper, as shown in Figure 5.

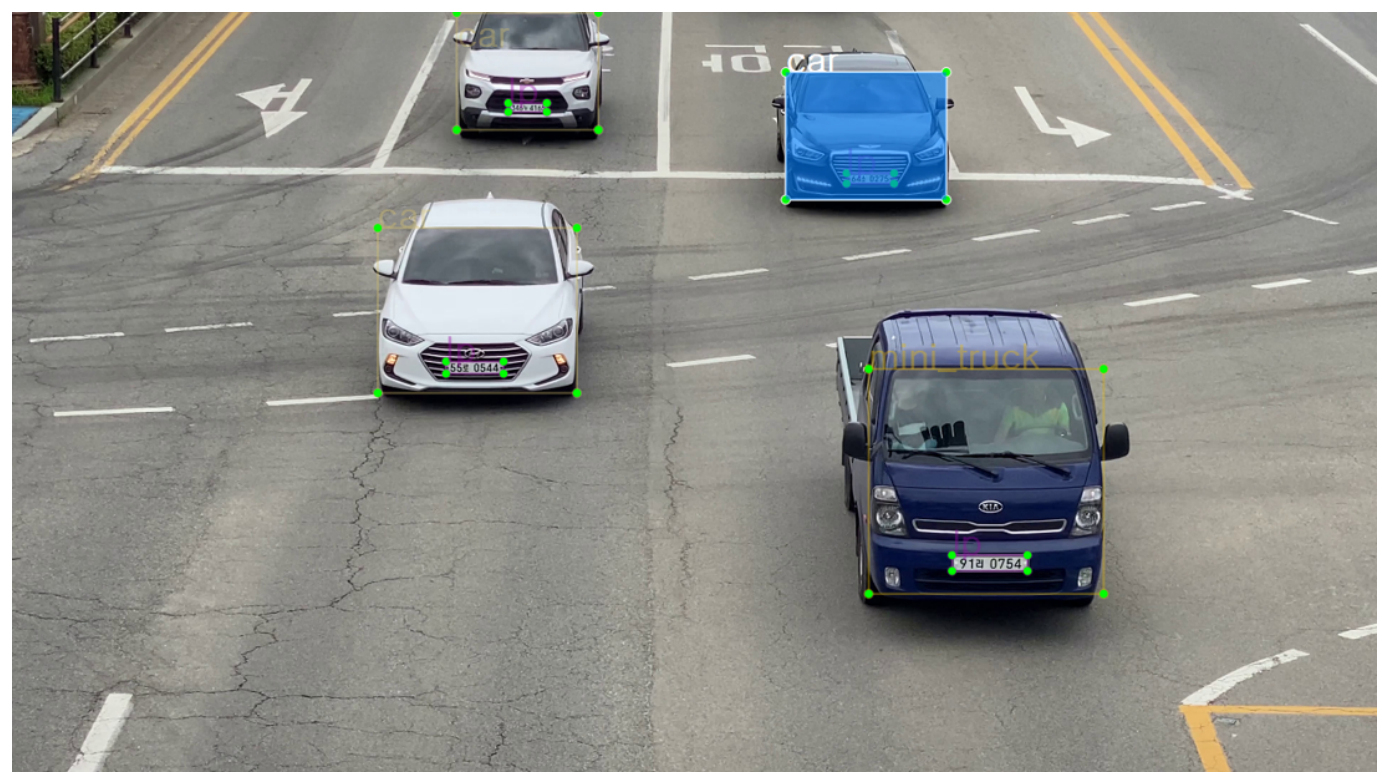

Figure 5. Labeling of vehicle types and license plates to be used for phase 1.

To label different vehicle types, we referenced a vehicle classification according to the vehicle size and passenger capacity used by the Korea Expressway Corporation (https: / / www.ex.co.kr/portal/usefee/selectUseFeeNList.do, accessed on 7 December 2021). We classified vehicles into six categories based on the vehicle size and passenger capacity. The smallest vehicles or compact cars were labeled as 'compact'. Vehicles capable of holding nine or fewer passengers were labeled as 'car'. Vehicles with a capacity of 25 or fewer passengers were labeled as 'mini van'. Big vans with 25 or more passengers were labeled as 'bus (big van)'. Smaller two-axle freight vehicles were labeled as 'mini truck', and threeor-more-axle freight vehicles were labeled as 'truck'. The six vehicle types we labeled in our dataset are shown in Figure 6. Table 2 shows the collected dataset of six vehicle types and LPs. 


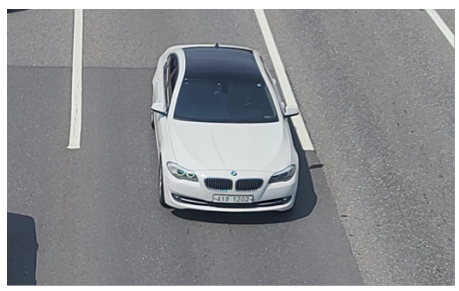

Car

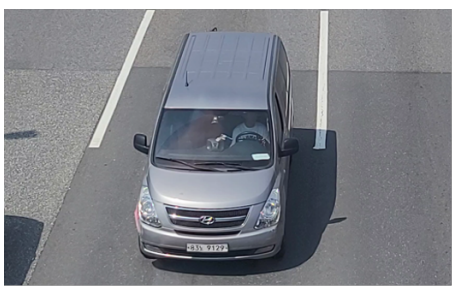

Mini Van

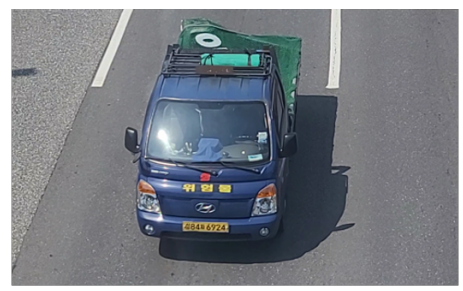

Mini Truck

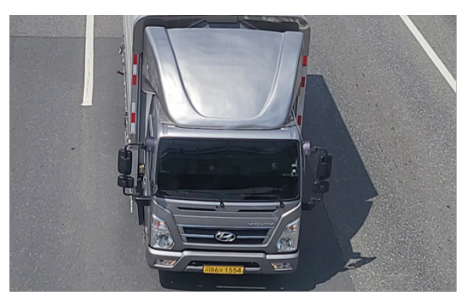

Truck

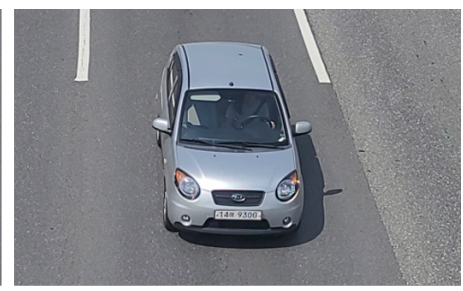

Compact

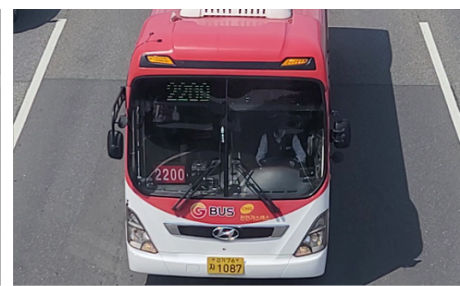

Bus

Figure 6. Classification of six vehicle types.

Table 2. Our dataset of six vehicle types and LPs with corresponding distribution ratio.

\begin{tabular}{lrrrrr}
\hline \multirow{2}{*}{ Classes } & Two & Three & Four & Total & Ratio (\%) \\
\cline { 2 - 6 } & 4063 & 2411 & 374 & 6878 & 57.1 \\
\hline License Plate & 1757 & 1159 & 230 & 3146 & 26.1 \\
Car & 563 & 275 & 41 & 879 & 7.3 \\
Mini Truck & 292 & 170 & 38 & 500 & 4.2 \\
Compact & 282 & 97 & 15 & 394 & 3.3 \\
Mini Van & 110 & 59 & 12 & 181 & 1.5 \\
Truck & 48 & 13 & 5 & 66 & 0.6 \\
Bus & 7115 & 4184 & 715 & 12,044 & 100.0 \\
\hline Total & & & & & \\
\hline
\end{tabular}

\subsubsection{LP Numbers and Characters}

The recorded videos were also used to manually label Korean LP numbers and characters. We also took additional pictures of LPs with a smartphone camera. LP areas were segmented and used as training data from these sources. In the case of LPs, a bounding box was drawn over the four vertices of an LP. Furthermore, bounding boxes were annotated on each number or character on LPs, as shown in Figure 7.

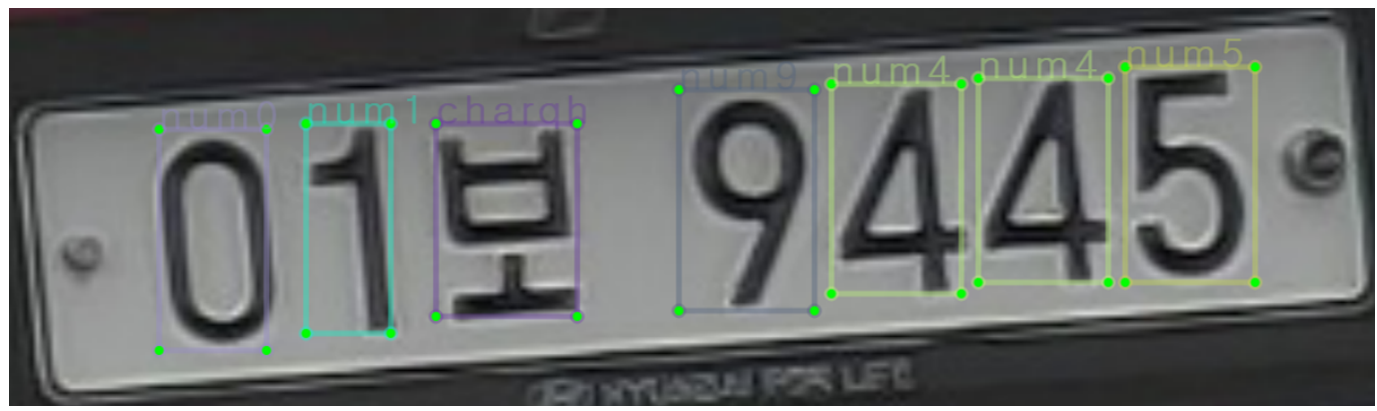

Figure 7. Labeling of LP numbers and characters to be used for phase 2.

Over 60,000 occurrences of Korean LP numbers and characters were collected and grouped into 68 classes (i.e., numbers 0 to 9: class 0 to 9, 41 Korean characters: class 10 to 50 , and 17 local area prefixes: class 51 to 67). Figure 8 shows different Korean LP styles, including single-line and double-line LPs. Area prefixes and predesignated Korean characters can be found on older LPs and special-purpose vehicles. Tables 3 and 4 show 
the collected dataset for Korean LP numbers and characters. Note that we were not able to collect all LP characters, and numerous local area prefixes were left out (highlighted in gray in Table 4).

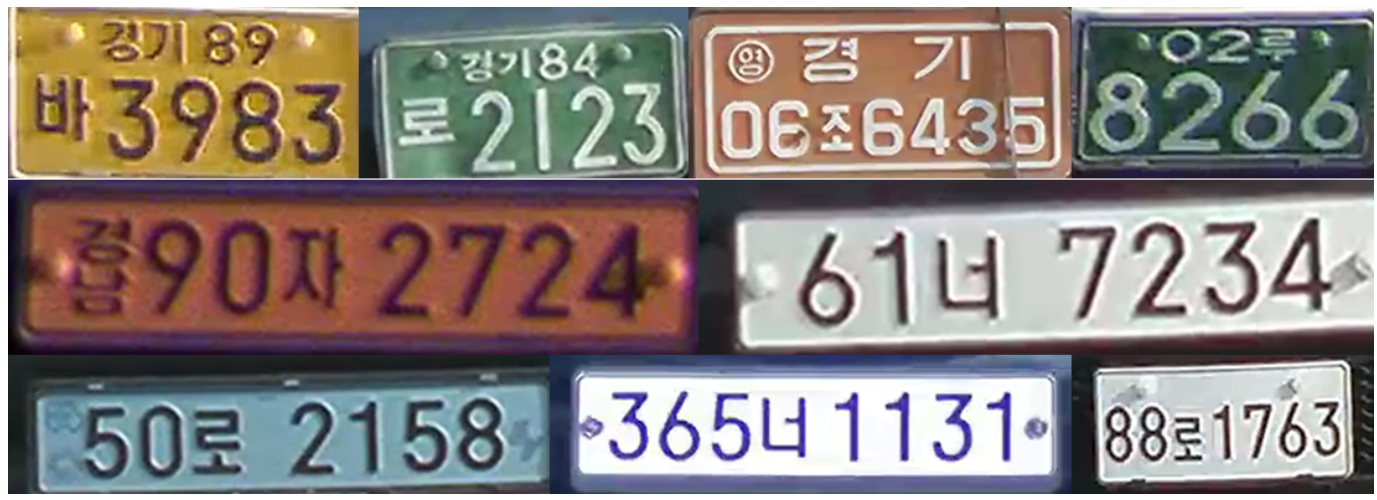

Figure 8. Different Korean LP styles, including single- and double-line LPs containing Korean characters and numbers listed in Tables 3 and 4.

Table 3. Collected data for Korean LP numbers.

\begin{tabular}{lrrrrr}
\hline Class & Character & Training & Validation & Test & Total \\
\hline 0 & 0 & 4560 & 871 & 686 & 6117 \\
1 & 1 & 4978 & 966 & 744 & 6688 \\
2 & 2 & 3850 & 680 & 583 & 5113 \\
3 & 3 & 4171 & 789 & 608 & 5568 \\
4 & 4 & 3644 & 657 & 510 & 4811 \\
5 & 5 & 3775 & 718 & 558 & 5051 \\
6 & 6 & 3431 & 598 & 510 & 4539 \\
7 & 7 & 3544 & 710 & 487 & 4741 \\
8 & 8 & 3449 & 635 & 473 & 4557 \\
9 & 9 & 3081 & 577 & 434 & 4092 \\
\hline & & 38,483 & 7201 & 5593 & 51,277 \\
\hline
\end{tabular}

Table 4. Collected data for Korean LP characters; classes 55, 57, 60, 61, 63, 64, and 67 were not sufficiently collected (highlighted in gray).

\begin{tabular}{|c|c|c|c|c|c|}
\hline Class & Character & Training & Validation & Test & Total \\
\hline 10 & 가 $(\mathrm{Ga})$ & 137 & 31 & 25 & 193 \\
\hline 11 & 거 (Geo) & 150 & 36 & 26 & 212 \\
\hline 12 & 고 $(\mathrm{Go})$ & 145 & 35 & 27 & 207 \\
\hline 13 & 구 $(\mathrm{Gu})$ & 140 & 32 & 24 & 196 \\
\hline 14 & 나 (Na) & 151 & 35 & 26 & 212 \\
\hline 15 & 너 (Neo) & 151 & 35 & 27 & 213 \\
\hline 16 & 노 $(\mathrm{No})$ & 141 & 31 & 26 & 198 \\
\hline 17 & 누 $(\mathrm{Nu})$ & 144 & 32 & 26 & 202 \\
\hline 18 & 다 $(\mathrm{Da})$ & 142 & 32 & 25 & 199 \\
\hline 19 & 더 (Deo) & 145 & 35 & 24 & 204 \\
\hline 20 & 도 $(\mathrm{Do})$ & 142 & 32 & 26 & 200 \\
\hline 21 & 두 $(\mathrm{Du})$ & 180 & 28 & 21 & 229 \\
\hline 22 & 라 (Ra) & 140 & 31 & 25 & 196 \\
\hline 23 & 러 (Reo) & 173 & 26 & 20 & 219 \\
\hline 24 & 로 (Ro) & 136 & 28 & 21 & 185 \\
\hline
\end{tabular}


Table 4. Cont.

\begin{tabular}{|c|c|c|c|c|c|}
\hline Class & Character & Training & Validation & Test & Total \\
\hline 25 & 루 $(\mathrm{Ru})$ & 217 & 35 & 27 & 279 \\
\hline 26 & 마 (Ma) & 185 & 26 & 20 & 231 \\
\hline 27 & 머 (Meo) & 154 & 35 & 27 & 216 \\
\hline 28 & 모 (Mo) & 182 & 26 & 20 & 228 \\
\hline 29 & 무 (Mu) & 153 & 35 & 27 & 215 \\
\hline 30 & 바 (Ba) & 656 & 168 & 120 & 944 \\
\hline 31 & 배 (Bae) & 33 & 10 & 6 & 49 \\
\hline 32 & 버 (Beo) & 141 & 32 & 26 & 199 \\
\hline 33 & 보 (Bo) & 164 & 19 & 16 & 199 \\
\hline 34 & 부 (Bu) & 163 & 15 & 13 & 191 \\
\hline 35 & 사 $(\mathrm{Sa})$ & 106 & 27 & 21 & 154 \\
\hline 36 & 서 (Seo) & 126 & 11 & 9 & 146 \\
\hline 37 & 소 (So) & 124 & 12 & 9 & 145 \\
\hline 38 & 수 $(\mathrm{Su})$ & 115 & 13 & 11 & 139 \\
\hline 39 & 아 (A) & 259 & 52 & 46 & 357 \\
\hline 40 & 어 (Eo) & 115 & 18 & 15 & 148 \\
\hline 41 & 영 (Yeong) & 54 & 12 & 9 & 75 \\
\hline 42 & 오 $(\mathrm{O})$ & 124 & 17 & 15 & 156 \\
\hline 43 & 우 (U) & 132 & 8 & 8 & 148 \\
\hline 44 & 자 (Ja) & 264 & 53 & 37 & 354 \\
\hline 45 & 저 (Jeo) & 116 & 14 & 12 & 142 \\
\hline 46 & 조 (Jo) & 115 & 16 & 11 & 142 \\
\hline 47 & 주 $(\mathrm{Ju})$ & 137 & 13 & 10 & 160 \\
\hline 48 & 하 (Ha) & 125 & 15 & 13 & 153 \\
\hline 49 & 허 (Heo) & 117 & 17 & 17 & 151 \\
\hline 50 & 호 (Ho) & 134 & 32 & 19 & 185 \\
\hline 51 & 강원 (Gangwon) & 136 & 35 & 22 & 193 \\
\hline 52 & 경기 (Gyeonggi) & 187 & 44 & 38 & 269 \\
\hline 53 & 경남 (Gyeongnam) & 106 & 25 & 16 & 147 \\
\hline 54 & 경북 (Gyeongbuk) & 51 & 11 & 9 & 71 \\
\hline 55 & 광주 (Gwangju) & 5 & 0 & 0 & 5 \\
\hline 56 & 대구 (Daegu) & 98 & 22 & 16 & 136 \\
\hline 57 & 대전 (Daejeon) & 0 & 0 & 0 & 0 \\
\hline 58 & 부산 (Busan) & 20 & 5 & 3 & 28 \\
\hline 59 & 서울 (Seoul) & 283 & 67 & 52 & 402 \\
\hline 60 & 세종 (Sejong) & 0 & 0 & 0 & 0 \\
\hline 61 & 울산 (Ulsan) & 3 & 0 & 0 & 3 \\
\hline 62 & 인천 (Incheon) & 165 & 39 & 29 & 233 \\
\hline 63 & 전남 (Jeonnam) & 5 & 0 & 1 & 6 \\
\hline 64 & 전북 (Jeonbuk) & 3 & 0 & 0 & 3 \\
\hline 65 & 충남 (Chungnam) & 331 & 76 & 60 & 467 \\
\hline 66 & 충북 (Chungbuk) & 11 & 1 & 1 & 13 \\
\hline 67 & 제주 (Jeju) & 0 & 0 & 0 & 0 \\
\hline \multicolumn{2}{|r|}{ Total } & 7832 & 1535 & 1180 & 10,547 \\
\hline
\end{tabular}

\section{Experiments}

To evaluate the feasibility and effectiveness of the KVT-LPR system, we evaluated the KVT-LPR system's capability of detecting small LPs, detection speed, the performance of vehicle type detection, and the performance of LPR.

\subsection{Implementation}

To implement our proposed KVT-LPR system, we used YOLOv4 [12] as the underlying object detector. We used an open-source darknet framework to train YOLOv4 to detect our custom set of classes (i.e., vehicle types, LP, and LP characters). We had previously experimented with several image input sizes before settling on a $256 \times 256$ image input size for YOLOv4 [24]. We discovered a considerable performance decrease on the lower- 
end embedded platform, despite the fact that a bigger input size, such as 608 , increased accuracy.

Figures 9 and 10 show the training loss and the mean average precision at $50 \%$ intersection-over-union threshold (mAP @ 0.5). For the VT_LP detector, the collected dataset was used as $70 \%$ train, $17.5 \%$ validation, and $12.5 \%$ test sets for each class. For the LPC detector, we used the collected dataset as $80 \%$ train and $20 \%$ test sets for all classes.

\subsection{Minimum Detectable LP Size}

The KVT-LPR aims to recognize multiple vehicle types and LPs in multilane highways. This means that the size of LPs will be small even in high-resolution images (i.e., $4 \mathrm{~K}$ resolution) when multiple lanes are observed. To see how our system performs on multilane images, we recorded the detected LPs' sizes by running test images of one-lane, two-lane, three-lane, and four-lane highways, respectively. The recorded LP sizes were sorted in ascending order of width. For brevity of results, we calculated the average of the first 100 ordered LP sizes. Table 5 shows the smallest 20 LP sizes for each lane with the calculated average. The average LP sizes in the different lanes are visualized in Figure 11.

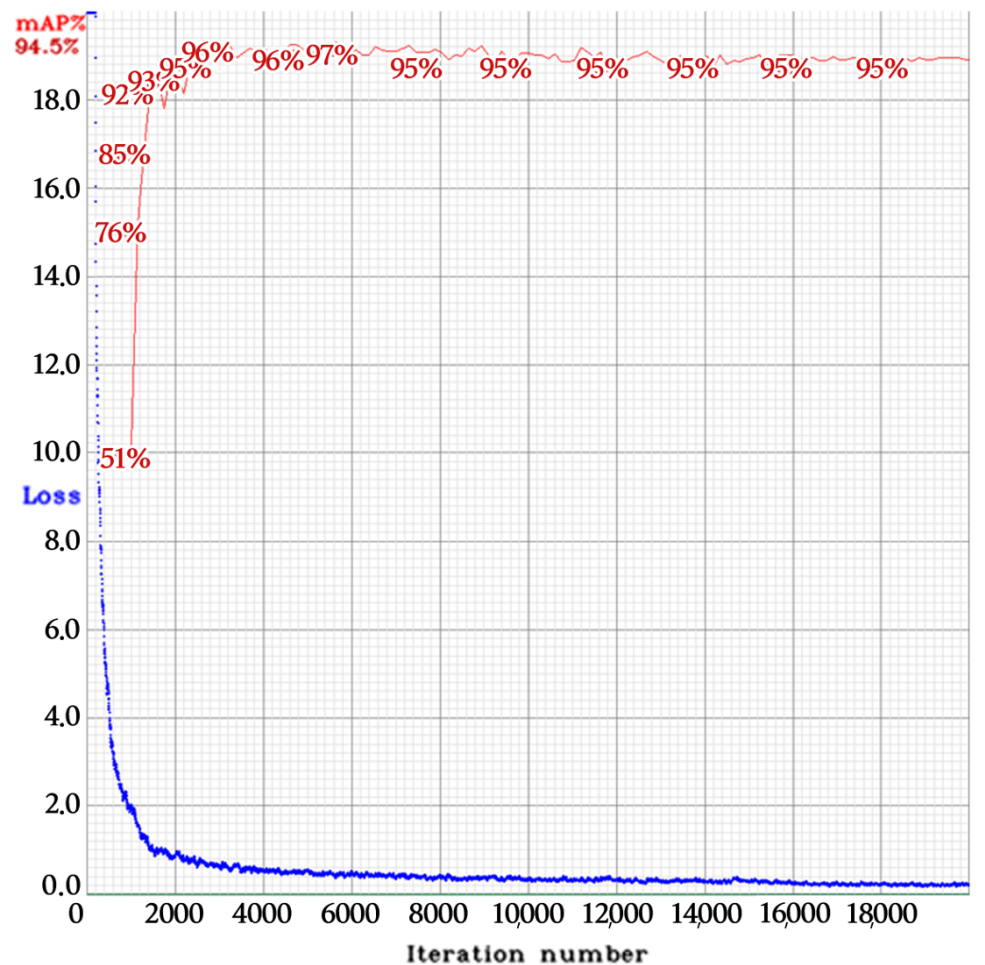

Figure 9. Training loss (blue) and mAP @ 0.5 (red) of the VT_LP detector in phase 1. 


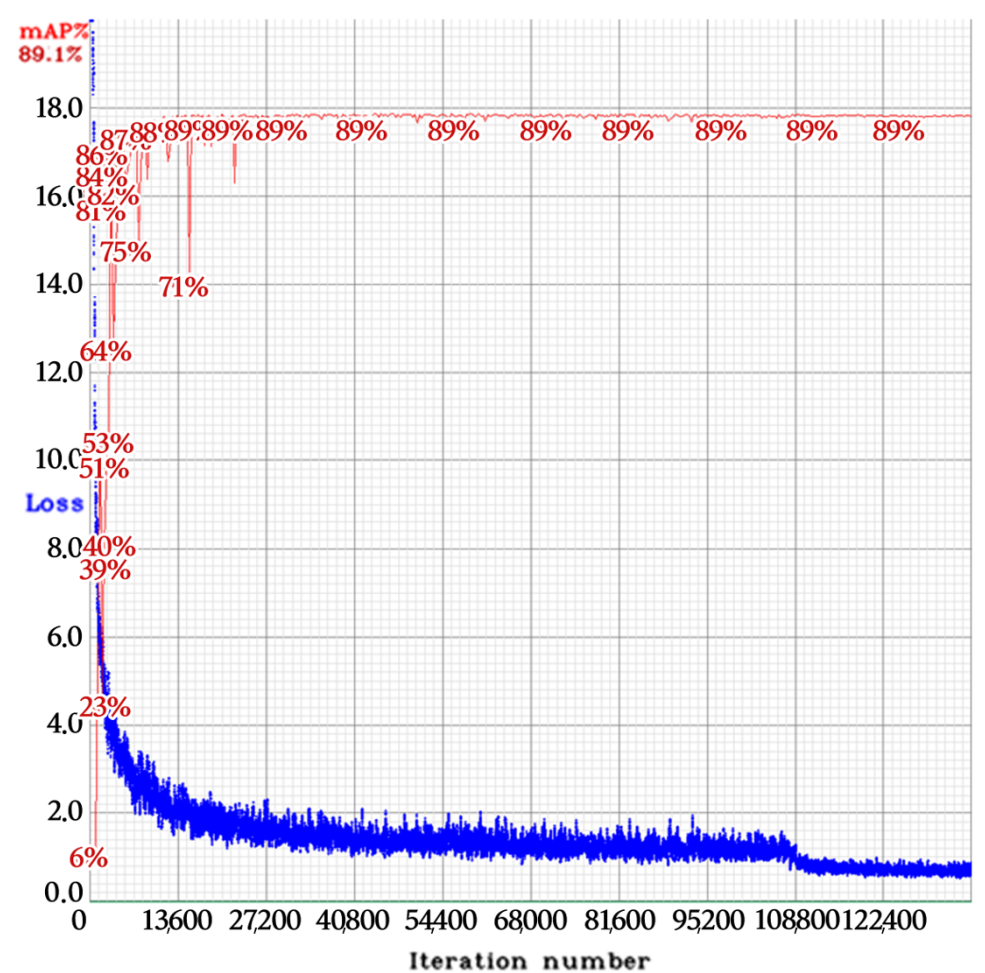

Figure 10. Training loss (blue) and mAP @ 0.5 (red) of the LPC detector in phase 2.

Table 5. Successfully detected smallest LPs in ascending order of their widths.

\begin{tabular}{|c|c|c|c|c|c|c|c|c|c|c|c|c|c|c|c|c|}
\hline & \multicolumn{4}{|c|}{ One-Lane } & \multicolumn{4}{|c|}{ Two-Lane } & \multicolumn{4}{|c|}{ Three-Lane } & \multicolumn{4}{|c|}{ Four-Lane } \\
\hline & \multicolumn{2}{|c|}{ Single-Line LP } & \multicolumn{2}{|c|}{ Double-Line LP } & \multicolumn{2}{|c|}{ Single-Line LP } & \multicolumn{2}{|c|}{ Double-Line LP } & \multicolumn{2}{|c|}{ Single-Line LP } & \multicolumn{2}{|c|}{ Double-Line LP } & \multicolumn{2}{|c|}{ Single-Line LP } & \multicolumn{2}{|c|}{ Double-Line LP } \\
\hline & Width & Height & Width & Height & Width & Height & Width & Height & Width & Height & Width & Height & Width & Height & Width & Height \\
\hline 1 & 286 & 94 & 250 & 137 & 149 & 49 & 119 & 72 & 96 & 32 & 102 & 36 & 113 & 36 & 106 & 59 \\
\hline 2 & 309 & 34 & 258 & 149 & 159 & 48 & 125 & 70 & 96 & 25 & 102 & 44 & 113 & 36 & 106 & 43 \\
\hline 3 & 364 & 90 & 258 & 137 & 164 & 40 & 133 & 75 & 97 & 32 & 102 & 59 & 115 & 35 & 106 & 51 \\
\hline 4 & 372 & 54 & 261 & 140 & 164 & 34 & 133 & 65 & 99 & 22 & 102 & 54 & 115 & 33 & 108 & 52 \\
\hline 5 & 372 & 87 & 262 & 138 & 165 & 36 & 133 & 77 & 99 & 26 & 102 & 50 & 118 & 35 & 108 & 58 \\
\hline 6 & 374 & 96 & 262 & 143 & 165 & 38 & 134 & 75 & 100 & 30 & 102 & 44 & 118 & 32 & 111 & 44 \\
\hline 7 & 378 & 90 & 266 & 126 & 166 & 38 & 136 & 65 & 100 & 25 & 102 & 50 & 119 & 35 & 112 & 65 \\
\hline 8 & 382 & 35 & 267 & 133 & 166 & 44 & 137 & 75 & 100 & 26 & 102 & 46 & 119 & 37 & 116 & 54 \\
\hline 9 & 384 & 81 & 270 & 142 & 166 & 27 & 137 & 68 & 101 & 27 & 103 & 55 & 119 & 35 & 116 & 67 \\
\hline 10 & 384 & 89 & 270 & 147 & 166 & 37 & 137 & 70 & 101 & 26 & 103 & 53 & 119 & 35 & 117 & 62 \\
\hline 11 & 384 & 96 & 272 & 119 & 167 & 32 & 139 & 73 & 101 & 27 & 103 & 41 & 120 & 37 & 117 & 54 \\
\hline 12 & 387 & 52 & 273 & 118 & 167 & 38 & 140 & 68 & 101 & 26 & 103 & 55 & 120 & 27 & 118 & 44 \\
\hline 13 & 388 & 89 & 274 & 153 & 168 & 33 & 140 & 70 & 101 & 16 & 103 & 52 & 121 & 35 & 119 & 75 \\
\hline 14 & 391 & 95 & 276 & 156 & 169 & 34 & 140 & 67 & 102 & 32 & 103 & 56 & 121 & 34 & 119 & 58 \\
\hline 15 & 391 & 89 & 278 & 155 & 169 & 41 & 140 & 69 & 102 & 33 & 103 & 37 & 121 & 35 & 119 & 60 \\
\hline 16 & 392 & 84 & 278 & 156 & 170 & 39 & 140 & 63 & 102 & 29 & 103 & 54 & 121 & 37 & 122 & 75 \\
\hline 17 & 393 & 98 & 280 & 136 & 170 & 35 & 141 & 75 & 104 & 27 & 103 & 57 & 121 & 34 & 122 & 65 \\
\hline 18 & 393 & 91 & 280 & 143 & 170 & 35 & 141 & 68 & 104 & 21 & 103 & 52 & 121 & 36 & 123 & 64 \\
\hline 19 & 395 & 95 & 280 & 151 & 170 & 40 & 142 & 90 & 104 & 28 & 103 & 51 & 121 & 29 & 124 & 71 \\
\hline 20 & 395 & 65 & 280 & 152 & 171 & 38 & 143 & 71 & 104 & 27 & 103 & 48 & 122 & 32 & 124 & 58 \\
\hline Average & 408 & 89 & 304 & 155 & 176 & 39 & 153 & 73 & 108 & 27 & 105 & 54 & 126 & 35 & 140 & 69 \\
\hline
\end{tabular}




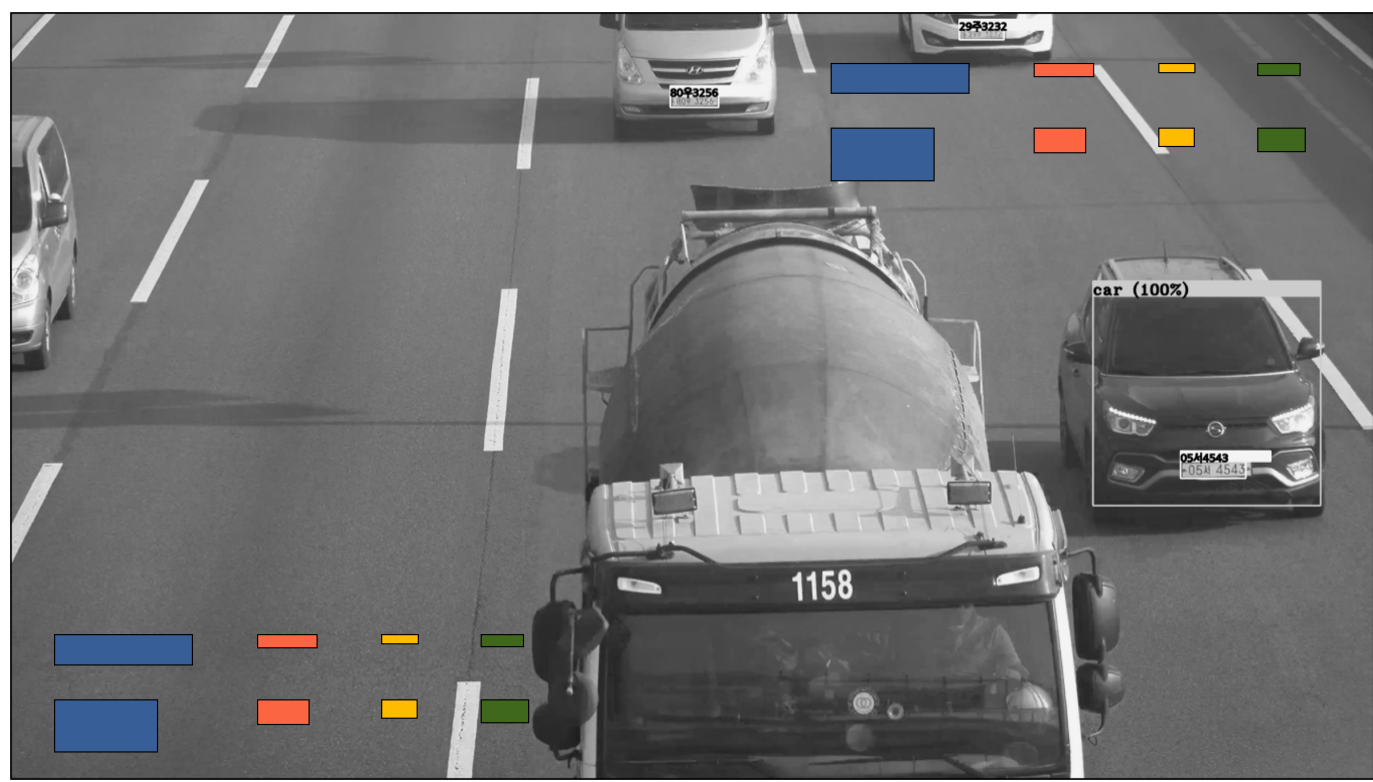

Figure 11. License plate sizes in one-lane, two-lane, three-lane, and four-lane images, represented to scale on $3840 \times 2160$ resolution.

\subsection{Detection Speed}

To measure the detection speed of the KVT-LPR, we used images that contain one car and one LP per lane. This means that one-lane test images (33 images) contained one car and one LP, and two-lane test images (20 images) contained two cars and two LPs. Likewise, three-lane test images (22 images) contained three cars and three LPs, and four-lane test images (19 images) contained four cars and four LPs. Figure 12 shows the examples of test images.

The detection speed is defined as the time it takes to detect vehicle type and LP (phase 1 , VT LP detector) and the time it takes to recognize LP characters from a cropped LP image (phase 2, LPC detector). Two platforms running Ubuntu 18.04 were evaluated: a PC with an RTX3090 graphics card (representing a high-end specification, GeForce RTX3090, NVIDIA CUDA Cores 10496, memory 24 GB, AMD Ryzen 7 3700X 8-core processor, 16 GB main memory) and a Jetson AGX Xavier (representing a low-end or embedded specification, 512-core NVIDIA Volta ${ }^{\mathrm{TM}}$ GPU with 64 tensor cores, 8-core ARM $^{\circledR}$ v8.2 64-bit CPU, 8 MB L2 + 4 MB L3, 32 GB 256-bit LPDDR4x | 137GB/s, 32GB eMMC 5.1). Tables 6 and 7 show the measured detection speed on two platforms. The detection speed for the VT_LP detector or phase 1 is comparable across different multilanes. However, the detection speed for the LPC detector or phase 2 is significantly reduced. This can be explained by the fact that the VT_LP detector detects only seven classes, whereas the LPC detector detects a magnitude more classes. 


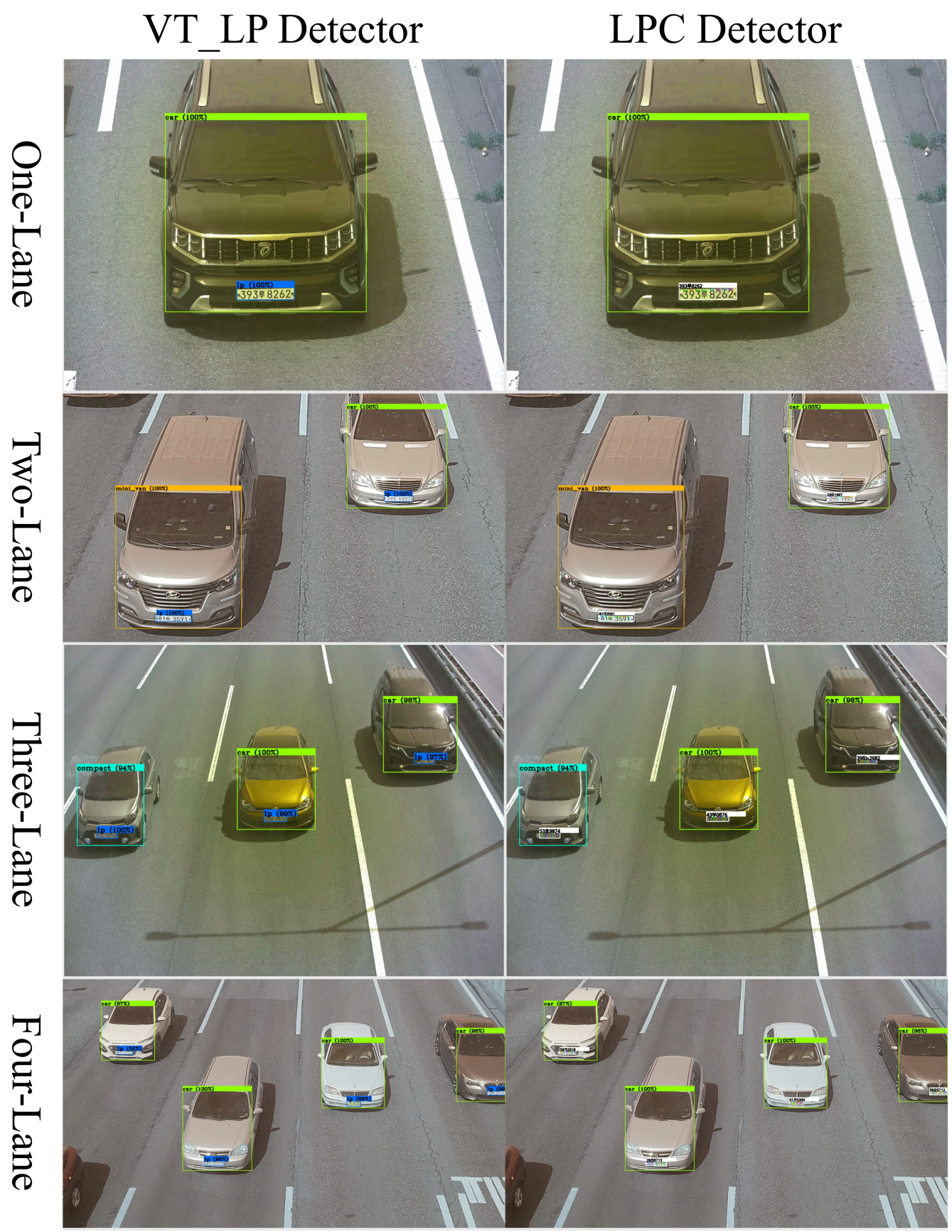

Figure 12. Examples of multilane test images for measuring detection speed.

Table 6. Detection speed on a PC with RTX3090.

\begin{tabular}{|c|c|c|c|c|c|c|c|c|}
\hline & \multicolumn{2}{|c|}{ One-Lane } & \multicolumn{2}{|c|}{ Two-Lane } & \multicolumn{2}{|c|}{ Three-Lane } & \multicolumn{2}{|c|}{ Four-Lane } \\
\hline & $\begin{array}{r}\text { Elapsed Time } \\
(\mathrm{ms})\end{array}$ & FPS & $\begin{array}{r}\text { Elapsed Time } \\
\text { (ms) }\end{array}$ & FPS & $\begin{array}{r}\text { Elapsed Time } \\
(\mathrm{ms})\end{array}$ & FPS & $\begin{array}{r}\text { Elapsed Time } \\
(\mathrm{ms})\end{array}$ & FPS \\
\hline VT_LP detector & 7.16 & 139.71 & 7.28 & 137.34 & 7.99 & 125.08 & 8.33 & 120.10 \\
\hline LPC detector & 17.70 & 56.51 & 29.81 & 33.55 & 44.22 & 22.62 & 54.42 & 18.38 \\
\hline
\end{tabular}


Table 7. Detection speed on Jetson AGX.

\begin{tabular}{|c|c|c|c|c|c|c|c|c|}
\hline & \multicolumn{2}{|c|}{ One-Lane } & \multicolumn{2}{|c|}{ Two-Lane } & \multicolumn{2}{|c|}{ Three-Lane } & \multicolumn{2}{|c|}{ Four-Lane } \\
\hline & $\begin{array}{r}\text { Elapsed Time } \\
\text { (ms) }\end{array}$ & FPS & $\begin{array}{r}\text { Elapsed Time } \\
\text { (ms) }\end{array}$ & FPS & $\begin{array}{r}\text { Elapsed Time } \\
\text { (ms) }\end{array}$ & FPS & $\begin{array}{r}\text { Elapsed Time } \\
\text { (ms) }\end{array}$ & FPS \\
\hline VT_LP detector & 60.68 & 16.48 & 61.74 & 16.20 & 63.35 & 15.79 & 64.25 & 15.56 \\
\hline LPC detector & 133.44 & 7.49 & 220.26 & 4.54 & 309.44 & 3.23 & 375.08 & 2.67 \\
\hline
\end{tabular}

\subsection{Vehicle Type and LP Detection Performance}

In the KVT-LPR, the VT_LP detector detects seven classes (LP and six vehicle types). To evaluate the performance of the VT_LP detector, we used typical metrics used for object detection, including precision (Equation (1)), recall (Equation (2)), F1-score (Equation (3)), average IOU (Equation (4)), average precision (Equation (5)), and mAP (Equation (6)).

$$
\begin{gathered}
\text { Precision }(\mathrm{P})=\frac{T P}{T P+F P} \\
\text { Recall }(\mathrm{R})=\frac{T P}{T P+F N} \\
\text { F1-score }=\frac{2 \times P \times R}{P+R} \\
\text { Average IOU }=\frac{T P}{T P+F P+T N} \\
\text { Average Precision }(\mathrm{AP})=\sum_{n}\left(R_{n}-R_{n-1}\right) P_{n} \\
\mathrm{mAP}=\frac{1}{N} \sum_{i=1}^{N} A P_{i}
\end{gathered}
$$

We ran the VT_LP detector with 222 one-lane, 140 two-lane, 183 three-lane, and 133 four-lane test set images, respectively. The vehicle type and LP detection results are shown in Tables 8 and 9. Our detector stably performed for one-lane, two-lane, and three-lane test images, demonstrating mAPs of $98.0 \%, 94.0 \%$, and $97.1 \%$, respectively. The most complicated scenario, four-lane, yielded an mAP of $84.6 \%$. The most common cause of failure on three- and four-lane highways is incorrect detection of partially contained vehicles in the upper zone. This can be avoided by pushing the recognition area to the center of the image.

Table 8. Vehicle type and LP detection, $\mathrm{mAP}$ at IOU $=0.5$.

\begin{tabular}{lrrrr}
\hline \multicolumn{1}{c}{ Class } & \multicolumn{4}{c}{ Average Precision } \\
& One-Lane & Two-Lane & Three-Lane & Four-Lane \\
\hline License Plate & 99.4 & 99.9 & 98.1 & 95.2 \\
Car & 99.9 & 93.9 & 94.5 & 95.0 \\
Mini Truck & 99.4 & 99.6 & 97.2 & 98.4 \\
Compact & 87.5 & 75.0 & 98.1 & 75.0 \\
Mini Van & 99.4 & 90.0 & 94.6 & 69.4 \\
Truck & 100.0 & 100.0 & 100.0 & 75.0 \\
Bus & 100.0 & 100.0 & 100.0 & 100.0 \\
\hline mAP & 98.0 & 94.0 & 97.1 & 84.6 \\
\hline
\end{tabular}

Table 9. Performance of the VT_LP detector.

\begin{tabular}{lrrrr}
\hline & One-Lane & Two-Lane & Three-Lane & Four-Lane \\
\hline Precision & 0.98 & 0.92 & 0.92 & 0.87 \\
Recall & 0.99 & 0.97 & 0.98 & 0.94 \\
F1-score & 0.99 & 0.95 & 0.95 & 0.90 \\
Average IOU $(\%)$ & 90.3 & 87.5 & 90.8 & 77.8 \\
\hline
\end{tabular}


Figure 13 shows examples of successfully detected vehicle types with the VT_LP detector.
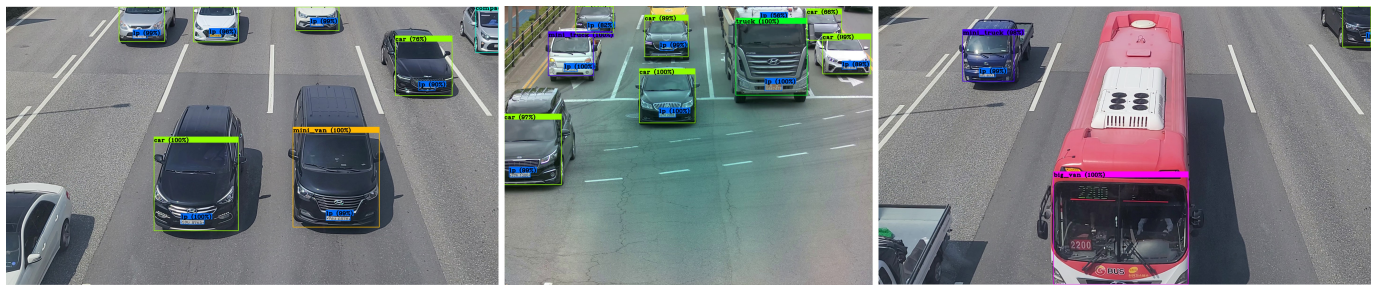

Figure 13. Examples of successfully detected vehicle types ( car , mini van , mini truck, truck bus ) with the VT_LP detector in phase 1.

\subsection{License Plate Recognition Performance}

Phase 2 of the proposed KVT-LPR system was evaluated according to the same metrics. The LPC detector detects 68 classes (i.e., numbers 0 to 9, 17 local area prefixes, and 41 Korean characters). First, we used our custom dataset to evaluate the performance of the LPC detector. As mentioned earlier, our dataset does not include several local area prefixes (i.e., 광주 (Gwangju), 대전 (Daejeon), 세종 (Sejong), 울산 (Ulsan), 전남 (Jeonnam), 전북 (Jeonbuk), 제주 (Jeju) ). Additionally, we used a publicly available LP dataset from AIHub (https: / / aihub.or.kr/aidata/27727, accessed on 7 December 2021). This open dataset includes 100,000 cropped car number plates in JPG format. We excluded local area prefixes not collected in our dataset. We tried to gather another open dataset, such as KarPlate dataset [23], but it was no longer available due to legal issues. There are other approaches, such as synthetically generating LPs [26] and synthetic LP dataset (https:/ / www.idai.or. $\mathrm{kr} /$ user/data_market/detail.do?id=63af9c70-ce79-11eb-ba8d-eb1fdd80455f, accessed on 7 December 2021), but we only evaluated our detector with the real data. Figure 14 shows LPR results on our custom dataset. Figure 15 shows LPR results on the AI-Hub dataset.

Table 10 shows the performance of the LPC detector according to the evaluation metrics, and Table 11 shows the detailed per-class results. With relatively few false positives and false negatives, the LPC detector had an adjusted mAP (i.e., eliminating classes with no or sparse data) of $99.30 \%$ for our custom dataset and $99.41 \%$ for the publicly open AI-Hub dataset.
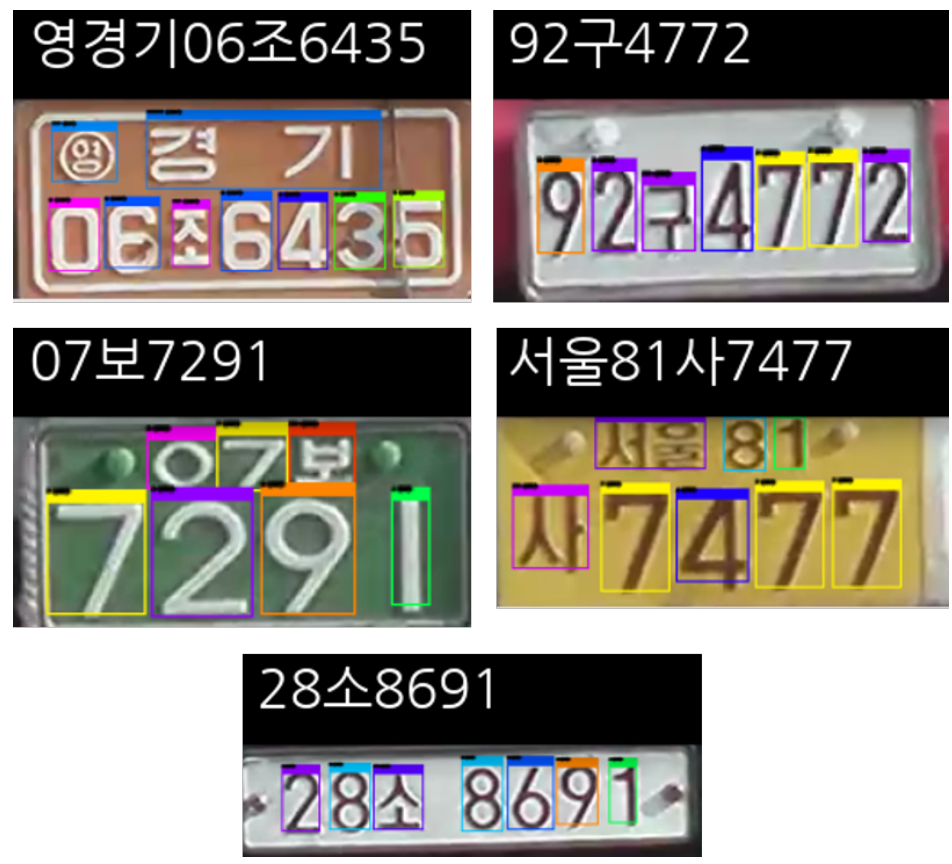

Figure 14. Output examples of the LPC detector in phase 2 using our dataset which reads as 'Yeong Gyeonggi 06 Jo 6435', '92 Gu 4772', '07 Bo 7291', 'Seoul 81 Sa 7477', and '28 So 8691', respectively. 

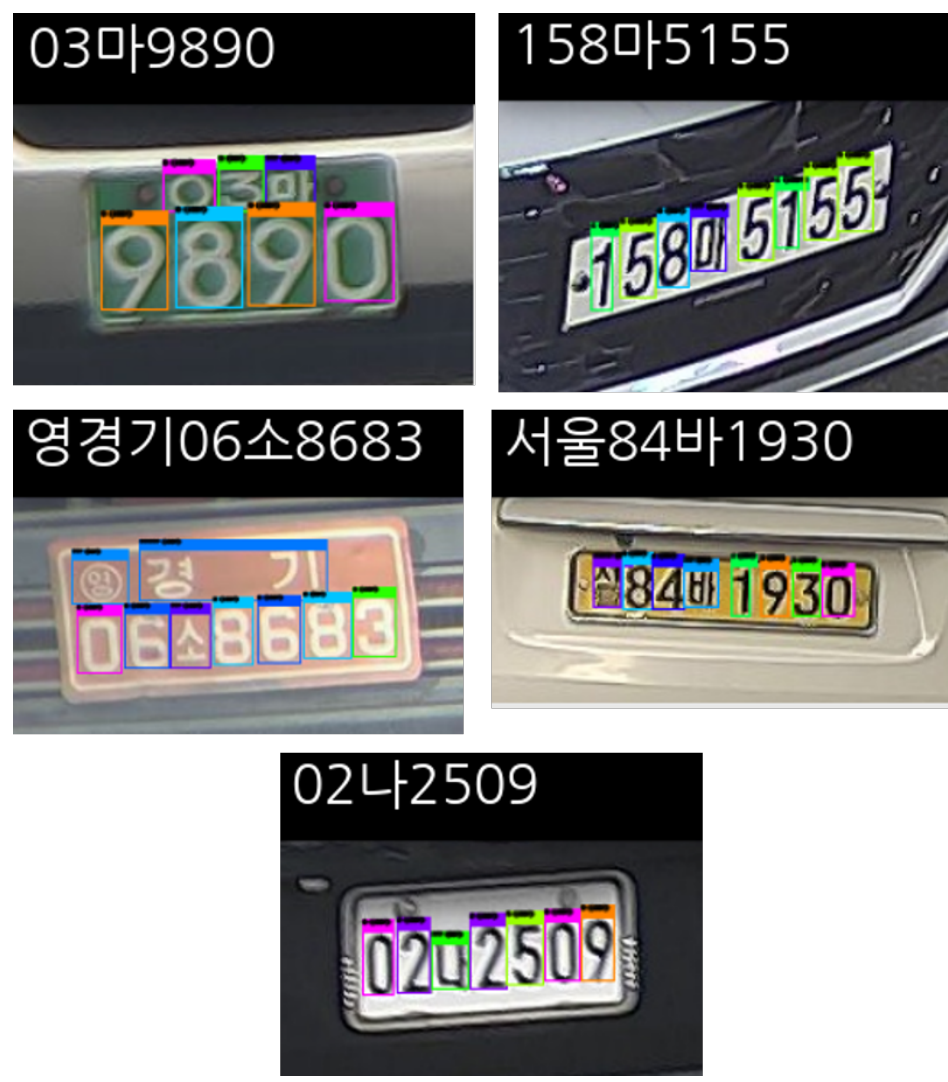

Figure 15. Output examples of the LPC detector in phase 2 using the AI-Hub dataset which reads as '03 Ma 9890', '158 Ma 5155', 'Yeong Gyeonggi 06 So 8683', 'Seoul 84 Ba 1930', and '02 Na 2509'.

Table 10. Performance of the LPC detector.

\begin{tabular}{lrr}
\hline & Our Dataset & AI-Hub Dataset \\
\hline Precision & 0.99 & 1.00 \\
Recall & 1.00 & 1.00 \\
F1-Score & 0.99 & 1.00 \\
Average IOU (\%) & 92.84 & 99.41 \\
\hline
\end{tabular}

Table 11. Performance of the LPC detector per class; classes highlighted in gray are excluded for adjusted results.

\begin{tabular}{ccccccc}
\hline \multirow{2}{*}{ Class } & \multicolumn{3}{c}{ Our Dataset } & \multicolumn{3}{c}{ AI-Hub Dataset } \\
\cline { 2 - 6 } & AP & TP & FP & AP & TP & FP \\
\hline 0 & 99.65 & 868 & 2 & 99.93 & 4470 & 3 \\
1 & 99.82 & 965 & 14 & 99.94 & 5538 & 11 \\
2 & 99.83 & 679 & 4 & 99.83 & 5051 & 26 \\
3 & 99.87 & 788 & 4 & 99.95 & 5599 & 9 \\
4 & 99.40 & 654 & 3 & 99.76 & 4451 & 5 \\
5 & 98.68 & 718 & 8 & 98.80 & 4724 & 4 \\
6 & 99.83 & 597 & 0 & 99.87 & 4742 & 5 \\
7 & 99.86 & 709 & 9 & 99.80 & 4421 & 22 \\
8 & 100.00 & 635 & 0 & 99.94 & 4824 & 6 \\
9 & 99.83 & 575 & 1 & 99.86 & 4186 & 0 \\
가 (Ga) & 100.00 & 31 & 2 & 99.90 & 198 & 0 \\
거 (Geo) & 97.07 & 34 & 0 & 98.49 & 197 & 5 \\
고 (Go) & 100.00 & 35 & 1 & 99.00 & 198 & 0 \\
구 (Gu) & 100.00 & 32 & 0 & 97.50 & 195 & 0 \\
\hline
\end{tabular}


Table 11. Cont.

\begin{tabular}{|c|c|c|c|c|c|c|}
\hline \multirow{2}{*}{ Class } & \multicolumn{3}{|c|}{ Our Dataset } & \multicolumn{3}{|c|}{ AI-Hub Dataset } \\
\hline & AP & TP & FP & $\mathbf{A P}$ & TP & FP \\
\hline 나 $(\mathrm{Na})$ & 97.14 & 34 & 0 & 100.00 & 199 & 0 \\
\hline 너 (Neo) & 99.68 & 35 & 1 & 99.99 & 200 & 3 \\
\hline 노 $(\mathrm{No})$ & 96.77 & 30 & 1 & 98.96 & 197 & 2 \\
\hline 누 $(\mathrm{Nu})$ & 100.00 & 32 & 0 & 98.51 & 198 & 0 \\
\hline 다 $(\mathrm{Da})$ & 100.00 & 32 & 0 & 99.49 & 199 & 2 \\
\hline 더 (Deo) & 97.06 & 33 & 0 & 96.50 & 193 & 0 \\
\hline 도 $(\mathrm{Do})$ & 100.00 & 32 & 2 & 98.50 & 197 & 3 \\
\hline 두 $(\mathrm{Du})$ & 100.00 & 28 & 0 & 99.85 & 200 & 10 \\
\hline 라 (Ra) & 100.00 & 31 & 0 & 100.00 & 198 & 0 \\
\hline 러 (Reo) & 100.00 & 26 & 0 & 99.47 & 196 & 6 \\
\hline 로 (Ro) & 89.70 & 25 & 11 & 96.26 & 193 & 2 \\
\hline 루 (Ru) & 92.14 & 32 & 9 & 98.92 & 198 & 13 \\
\hline 마 (Ma) & 100.00 & 26 & 0 & 99.00 & 198 & 1 \\
\hline 머 (Meo) & 99.86 & 35 & 0 & 96.05 & 195 & 4 \\
\hline 모 (Mo) & 100.00 & 25 & 0 & 98.79 & 197 & 3 \\
\hline 무 (Mu) & 100.00 & 35 & 0 & 98.17 & 197 & 1 \\
\hline 바 (Ba) & 100.00 & 168 & 1 & 98.80 & 249 & 2 \\
\hline 배 (Bae) & 100.00 & 10 & 0 & 0 & 0 & 0 \\
\hline 버 (Beo) & 100.00 & 32 & 0 & 99.99 & 200 & 4 \\
\hline 보 (Bo) & 100.00 & 19 & 0 & 99.99 & 200 & 4 \\
\hline 부 (Bu) & 100.00 & 15 & 0 & 99.99 & 201 & 5 \\
\hline 사 (Sa) & 99.87 & 26 & 0 & 93.73 & 198 & 2 \\
\hline 서 (Seo) & 100.00 & 11 & 0 & 99.98 & 200 & 22 \\
\hline 소 (So) & 100.00 & 12 & 0 & 99.99 & 199 & 4 \\
\hline 수 $(\mathrm{Su})$ & 100.00 & 13 & 0 & 99.99 & 200 & 4 \\
\hline 아 (A) & 100.00 & 52 & 0 & 97.13 & 203 & 0 \\
\hline 어 (Eo) & 100.00 & 18 & 0 & 96.96 & 193 & 3 \\
\hline 영 (Yeong) & 98.81 & 11 & 2 & 0 & 0 & 0 \\
\hline 오 (O) & 100.00 & 17 & 0 & 97.66 & 198 & 17 \\
\hline 우(U) & 100.00 & 8 & 0 & 98.99 & 197 & 1 \\
\hline 자 (Ja) & 100.00 & 53 & 0 & 90.04 & 208 & 0 \\
\hline 저 (Jeo) & 100.00 & 14 & 0 & 97.84 & 198 & 25 \\
\hline 조 (Jo) & 100.00 & 16 & 0 & 100 & 201 & 0 \\
\hline 주 $(\mathrm{Ju})$ & 100.00 & 13 & 0 & 98.48 & 195 & 0 \\
\hline 하 (Ha) & 100.00 & 15 & 0 & 99.48 & 200 & 2 \\
\hline 허 (Heo) & 100.00 & 17 & 0 & 99.31 & 198 & 7 \\
\hline 호 (Ho) & 100.00 & 32 & 0 & 89.59 & 178 & 1 \\
\hline 강원 (Gangwon) & 97.14 & 34 & 0 & 0 & 0 & 0 \\
\hline 경기 (Gyeonggi) & 100.00 & 44 & 3 & 96.36 & 159 & 0 \\
\hline 경남 (Gyeongnam) & 99.70 & 24 & 1 & 0 & 0 & 0 \\
\hline 경북 (Gyeongbuk) & 100.00 & 11 & 0 & 0 & 0 & 0 \\
\hline 광주 (Gwangju) & 0 & 0 & 0 & 0 & 0 & 0 \\
\hline 대구 (Daegu) & 100.00 & 22 & 0 & 0 & 0 & 0 \\
\hline 대전 (Daejeon) & 0 & 0 & 0 & 0 & 0 & 0 \\
\hline 부산 (Busan) & 100.00 & 5 & 0 & 0 & 0 & 0 \\
\hline 서울 (Seoul) & 99.98 & 66 & 1 & 97.83 & 724 & 2 \\
\hline 세종 (Sejong) & 0 & 0 & 0 & 0 & 0 & 0 \\
\hline 울산 (Ulsan) & 0 & 0 & 0 & 0 & 0 & 0 \\
\hline 인천 (Incheon) & 100.00 & 39 & 0 & 0 & 0 & 0 \\
\hline 전남 (Jeonnam) & 0 & 0 & 0 & 0 & 0 & 0 \\
\hline 전북 (Jeonbuk) & 0 & 0 & 0 & 0 & 0 & 0 \\
\hline 충남 (Chungnam) & 96.00 & 74 & 3 & 0 & 0 & 0 \\
\hline 충북 (Chungbuk) & 100.00 & 1 & 0 & 0 & 0 & 0 \\
\hline 제주 (Jeju) & 0 & 0 & 0 & 0 & 0 & 0 \\
\hline Total & 89.08 & 8703 & 83 & 73.87 & 56,648 & 251 \\
\hline Adjusted & 99.30 & 8703 & 83 & 99.41 & 56,648 & 251 \\
\hline
\end{tabular}




\subsection{Discussion}

Typical LPR systems use the camera view to monitor and check the LP of a single vehicle. The throughput (i.e., the number of LPs detected) of an LPR system can be enhanced and the deployment cost can be decreased if it can check multiple vehicles in several lanes. The proposed KVT-LPR showed that using multilane high-resolution images for LPR and vehicle type detection is possible. Table 5 shows how our system successfully detected small LP sizes of about 100 pixels. The KVT-LPR can be deployed on an embedded platform such as Jetson AGX. Table 7 shows that a standalone KVT-LPR configuration is feasible, but a networked-system (i.e., sending images to servers for recognition) approach can compensate for its shortcomings.

Our approach has some limitations. First, not all possible Korean LP styles and characters were collected in our dataset. Due to the geographical distance between other regions (i.e., cities and provinces) and our data collection location, several LPs with local area prefixes were left out. More data on those missing locations can be collected to improve our dataset. Second, the vehicle type detection can be improved by disregarding partially visible vehicles in images. In three-lane and four-lane images, those partially visible vehicles often resulted in failure cases. Third, our method assumes that the front view of the vehicle is captured. When the vehicle's rearview is used for recognition, vehicle type detection using the VT_LP detector is not possible due to this constraint. Regardless, LPR via the LPC detector works in both frontal and rear views. Lastly, as with many previous LPR studies, our dataset is not disclosed for legal reasons (i.e., obtaining the vehicle owner's consent for distribution and reuse).

\section{Conclusions}

This paper proposed KVT-LPR, a two-phase LPR system based on YOLOv4 for Korean vehicles and LPs. Using $4 \mathrm{~K}$ high-resolution input images, six vehicle types and LPs are detected by the VT_LP detector, followed by the LPC detector for LPR. The KVT-LPR is applicable to settings (i.e., highly populated and multilane highways in Korea) where the size of LPs is small. Across two datasets (our custom dataset and an open public dataset) and two target systems (RTX3090 and Jetson AGX), two custom detectors in the KVT-LPR demonstrated LPR performance suitable for both high-end and embedded platforms.

Our approach has limitations and drawbacks discussed in previous sections that deserve further research. For example, our dataset can be extended to include national coverage and special purpose vehicles. Moreover, to optimize LPR performance in designated settings (i.e., standalone, over-the-network, on edge devices), various network parameters, including image input size for YOLOv4 or other object detectors, can be compared, and trade-offs can be analyzed. Nonetheless, we have demonstrated the merits of our proposed KVT-LPR to effectively address Korean LPR with vehicle type detection that can be used in various complex smart city applications.

Author Contributions: Conceptualization, S.-H.P. and H.Y.; methodology, S.-H.P., S.-B.Y. and J.-A.K.; software, S.-B.Y. and J.-A.K.; validation, S.-H.P., S.-B.Y. and H.Y.; formal analysis, S.-B.Y. and H.Y.; investigation, S.-B.Y. and H.Y.; resources, S.-H.P.; data curation, J.-A.K. and S.-B.Y.; writing-original draft preparation, S.-H.P., S.-B.Y. and H.Y.; writing - review and editing, H.Y.; visualization, S.-B.Y. and H.Y.; supervision, S.-H.P. and H.Y.; project administration, S.-H.P.; funding acquisition, S.-H.P. All authors have read and agreed to the published version of the manuscript.

Funding: This work was supported by the IT R\&D program of MOTIE/KEIT (10077018, Development of integrated embedded platform and commercial prototype equipped with high-speed LPR function).

Institutional Review Board Statement: Not applicable.

Informed Consent Statement: All the participants are the authors themselves.

Acknowledgments: We thank the members of the Contents Convergence Research Center at KETI for their help in labeling the data we obtained for experiments. In Figure 1, photos with a free license to use were included for illustrative purposes. 
Conflicts of Interest: The authors declare no conflict of interest.

\section{References}

1. Gharaibeh, A.; Salahuddin, M.A.; Hussini, S.J.; Khreishah, A.; Khalil, I.; Guizani, M.; Al-Fuqaha, A. Smart Cities: A Survey on Data Management, Security, and Enabling Technologies. IEEE Commun. Surv. Tutor. 2017, 19, 2456-2501. [CrossRef]

2. Winkler, T.; Rinner, B. Security and Privacy Protection in Visual Sensor Networks: A Survey. ACM Comput. Surv. 2014, 47, 2. [CrossRef]

3. Baran, R.; Rusc, T.; Fornalski, P. A smart camera for the surveillance of vehicles in intelligent transportation systems. Multimed. Tools Appl. 2016, 75, 10471-10493. [CrossRef]

4. Won, M. Intelligent Traffic Monitoring Systems for Vehicle Classification: A Survey. IEEE Access 2020, 8, 73340-73358. [CrossRef]

5. Liu, L.; Ouyang, W.; Wang, X.; Fieguth, P.; Chen, J.; Liu, X.; Pietikäinen, M. Deep learning for generic object detection: A survey. Int. J. Comput. Vis. 2020, 128, 261-318. [CrossRef]

6. Anagnostopoulos, C.E.; Anagnostopoulos, I.E.; Psoroulas, I.D.; Loumos, V.; Kayafas, E. License Plate Recognition From Still Images and Video Sequences: A Survey. IEEE Trans. Intell. Transp. Syst. 2008, 9, 377-391. [CrossRef]

7. Shashirangana, J.; Padmasiri, H.; Meedeniya, D.; Perera, C. Automated License Plate Recognition: A Survey on Methods and Techniques. IEEE Access 2020, 9, 11203-11225. [CrossRef]

8. Du, S.; Ibrahim, M.; Shehata, M.; Badawy, W. Automatic license plate recognition (ALPR): A state-of-the-art review. IEEE Trans. Circuits Syst. Video Technol. 2013, 23, 311-325. [CrossRef]

9. Hsieh, J.; Chen, L.; Chen, D. Symmetrical SURF and Its Applications to Vehicle Detection and Vehicle Make and Model Recognition. IEEE Trans. Intell. Transp. Syst. 2014, 15, 6-20. [CrossRef]

10. Siddiqui, A.J.; Mammeri, A.; Boukerche, A. Real-Time Vehicle Make and Model Recognition Based on a Bag of SURF Features. IEEE Trans. Intell. Transp. Syst. 2016, 17, 3205-3219. [CrossRef]

11. Manzoor, M.A.; Morgan, Y.; Bais, A. Real-Time Vehicle Make and Model Recognition System. Mach. Learn. Knowl. Extr. 2019, 1, 611-629. [CrossRef]

12. Bochkovskiy, A.; Wang, C.-Y.; Liao, H.-Y.M. Yolov4: Optimal speed and accuracy of object detection. arXiv 2020, arXiv:2004.10934.

13. Liu, W.; Anguelov, D.; Erhan, D.; Szegedy, C.; Reed, S.; Fu, C.-Y.; Berg, A.C. SSD: Single shot MultiBox detector. In Proceedings of the European Conference on Computer Vision, Amsterdam, The Netherlands, 11-14 October 2016; Springer International Publishing: Cham, Switzerland, 2016; pp. 21-37.

14. Redmon, J.; Divvala, S.; Girshick, R.; Farhadi, A.You only look once: Unified, real-time object detection. In Proceedings of the IEEE Conference on Computer Vision and Pattern Recognition, Las Vegas, NV, USA, 27-30 June 2016; pp. 779-788.

15. Redmon, J.; Farhadi, A. YOLO9000: Better, faster, stronger. In Proceedings of the 2017 IEEE Conference on Computer Vision and Pattern Recognition (CVPR), Honolulu, HI, USA, 21-26 July 2017.

16. Redmon, J.; Farhadi, A. Yolov3: An incremental improvement. arXiv 2018, arXiv:1804.02767.

17. Hendry; Chen, R.-C. Automatic license plate recognition via sliding-window darknet-YOLO deep learning. Image Vis Comput. 2019, 87, 47-56. [CrossRef]

18. Laroca, R.; Zanlorensi, L.A.; Gonçalves, G.R.; Todt, E.; Schwartz, W.R.; Menotti, D. An efficient and layout-independent automatic license plate recognition system based on the YOLO detector. IET Intell. Transp. Syst. 2021, 15, 483-503. [CrossRef]

19. Castro-Zunti, R.D.; Yépez, J.; Ko, S.-B. License plate segmentation and recognition system using deep learning and OpenVINO. IET Intell. Transp. Syst. 2020, 14, 119-126. [CrossRef]

20. Han, B.-G.; Lee, J.T.; Lim, K.-T.; Chung, Y. Real-time license plate detection in high-resolution videos using fastest available cascade classifier and core patterns. ETRI J. 2015, 37, 251-261. [CrossRef]

21. Park, S.; Yoon, H.; Park, S. Multi-style license plate recognition system using k-nearest neighbors. KSII Trans. Internet Inf. Syst. (TIIS) 2019, 13, 2509-2528.

22. Kim, K.-J.; Kim, P.-K.; Chung, Y.-S.; Choi, D.-H. Multi-scale detector for accurate vehicle detection in traffic surveillance data. IEEE Access 2019, 7, 78311-78319. [CrossRef]

23. Henry, C.; Ahn, S.Y.; Lee, S.-W. Multinational license plate recognition using generalized character sequence detection. IEEE Access 2020, 8, 35185-35199. [CrossRef]

24. Sung, J.-Y.; Yu, S.-B.; Park, S.-H. Real-time automatic license plate recognition system using YOLOv4. In Proceedings of the 2020 IEEE International Conference on Consumer Electronics-Asia (ICCE-Asia), Seoul, Korea, 1-3 November 2020.

25. Kim, J.-A.; Sung, J.-Y.; Park, S.-H. Comparison of faster-RCNN, YOLO, and SSD for real-time vehicle type recognition. In Proceedings of the 2020 IEEE International Conference on Consumer Electronics-Asia (ICCE-Asia), Seoul, Korea, 1-3 November 2020.

26. Han, B.-G.; Lee, J.T.; Lim, K.-T.; Choi, D.-H. License plate image generation using generative adversarial networks for end-to-end license plate character recognition from a small set of real images. Appl. Sci. 2020, 10, 2780. [CrossRef]

27. Wang, H.; Li, Y.; Dang, L.-M.; Moon, H. Robust Korean license plate recognition based on deep neural networks. Sensors 2021, 21, 4140. [CrossRef]

28. Lim, D.; Park, D. AI analysis of illegal parking data at Seocho city. In Data Science and Digital Transformation in the Fourth Industrial Revolution, Studies in Computational Intelligence; Springer: Cham, Switzerland, 2021; Volume 929, pp. 165-178. 